\title{
Viability of the lichen Xanthoria elegans and its symbionts after 18 months of space exposure and simulated Mars conditions on the ISS
}

\author{
Annette Brandt ${ }^{\prime}$, Jean-Pierre de Vera ${ }^{2}$, Silvano Onofri ${ }^{3}$ and Sieglinde Ott ${ }^{\prime}$ \\ ${ }^{1}$ Institute of Botany, Heinrich-Heine-University, Universitätsstr. 1, 40225 Düsseldorf, Germany \\ ${ }^{2}$ Institute of Planetary Research, German Aerospace Center (DLR), Rutherfordstr. 2, 12489 Berlin, Germany \\ ${ }^{3}$ Department of Ecological and Biological Sciences (DEB), Tuscia University, Largo dell'Università, 01100 Viterbo, Italy \\ e-mail: otts@uni-duesseldorf.de
}

\begin{abstract}
The lichen Xanthoria elegans has been exposed to space conditions and simulated Mars-analogue conditions in the lichen and fungi experiment (LIFE) on the International Space Station (ISS). After several simulations and short space exposure experiments such as BIOPAN, this was the first long-term exposure of eukaryotic organisms to the hostile space conditions of the low Earth orbit (LEO). The biological samples were integrated in the EXPOSE-E facility and exposed for 1.5 years outside the ISS to the combined impact of insolation, ultraviolet (UV)-irradiation, cosmic radiation, temperatures and vacuum conditions of LEO space. Additionally, a subset of $X$. elegans samples was exposed to simulated Martian environmental conditions by applying Mars-analogue atmosphere and suitable solar radiation filters. After their return to Earth the viability of the lichen samples was ascertained by viability analysis of LIVE/DEAD staining and confocal laser-scanning microscopy, but also by analyses of chlorophyll $a$ fluorescence. According to the LIVE/DEAD staining results, the lichen photobiont showed an average viability rate of $71 \%$, whereas the even more resistant lichen mycobiont showed a rate of $84 \%$. Post-exposure viability rates did not significantly vary among the applied exposure conditions. This remarkable viability is discussed in the context of particular protective mechanisms of lichens such as anhydrobiosis and UV-screening pigments.
\end{abstract}

Received 10 February 2014, accepted 10 June 2014, first published online 24 July 2014

Key words: astrobiology, insolation, Lithopanspermia, mycobiont, photobiont, UV-resistance.

\section{Introduction}

Challenging effects of global transitions and a vast range of terrestrial ecological niches resulted in an enormous capacity of life to resist hostile environmental conditions and a broad range of adaptive mechanisms. To assess this resistance in the context of space conditions, numerable exposure- and simulation-experiments were conducted with micro-organisms originating from extreme arid, alpine and polar regions, including bacteria, biofilms, cryptoendolithic fungi and lichen symbioses (Onofri et al. 2004; de Vera et al. 2004a, b; de Vera et al. 2008; Hájek et al. 2012; Sadowsky \& Ott 2012; Baqué et al. 2013).

The study presented focuses on the lichen Xanthoria elegans (Link) Th.Fr. Lichens are symbiotic associations of photoautotrophic green algae or cyanobacteria (photobiont, PB) and heterotrophic fungi (mycobiont, MB). Lichen symbioses are characterized by high resistance to severe environmental conditions (Lange \& Kappen 1972; Kappen 1985; Hawksworth 1988; Lange 1990). Lichens developed a broad range of anatomical, morphological and physiological adaptions (Lange \& Kappen 1972; Ott \& Sancho 1991; Sadowsky \&
Ott 2012; Meeßen et al. 2013a, b). Moreover, all lichens are poikilohydric with the ability for anhydrobiosis (also called anabiosis), an inactive state of latent life while being desiccated (Crowe et al. 1992). Additionally, they frequently produce high amounts of secondary lichen compounds (Huneck \& Yoshimura 1996) which may provide protection against ultraviolet (UV) irradiation and/or excess photosynthetically active radiation (Solhaug \& Gauslaa 1996; Nybakken et al. 2004; Kranner et al. 2005). These adaptive traits enable the lichen symbiosis to colonize all biomes on Earth and adapt to the harsh environmental conditions of extreme habitats such as deserts, alpine and polar regions (aridity, cold, freeze-thaw cycles, high insolation) where they occasionally form the dominant vegetation (Kappen et al. 1996; Kappen \& Schroeter 1997; Kappen 2000; Sadowsky \& Ott 2012). Owing to these adaptions, lichens found some attention in astrobiological research (de Vera et al. 2003, 2004a, 2008, 2010; de la Torre et al. 2007, 2010a, b; Sancho et al. 2007; Stöffler et al. 2007; Horneck et al. 2008; de Vera \& Ott 2010; Raggio et al. 2011; Onofri et al. 2012; Sánchez et al. 2014) and were supposed to be astrobiological model organisms (Sancho et al. 2008). 
Prior to the lichen and fungi experiment (LIFE) on the International Space Station (ISS) the lichen species $X$. elegans was investigated in several experiments not only under real (LITHOPANSPERMIA on BIOPAN 6; de la Torre et al. 2010b; Raggio et al. 2011) but also under simulated space conditions that included stressors as desiccation, low Earth orbit (LEO)-vacuum of $10^{-5} \mathrm{~Pa}$, sub-zero temperatures, solar irradiation, cosmic radiation and shock pressure impacts (de Vera et al. 2003, 2004a, b; Stöffler et al. 2007; Horneck et al. 2008; Sancho et al. 2008; de Vera \& Ott 2010; Meyer et al. 2011). The studies demonstrated the high resistance of $X$. elegans towards hostile conditions and assessed the limits of life for extremotolerant organisms. Entire $X$. elegans thalli were neither significantly damaged by the combined influences of UV radiation (UVR) ( $\left.\lambda>160 \mathrm{~nm} ; 2.8 \mathrm{~W} \mathrm{~m}^{-2}, 16 \mathrm{~h}\right)$ and vacuum up to $10^{-3} \mathrm{~Pa}$ (de Vera et al. 2003) nor by the combined influences of UVR ( $\left.\lambda=200 \mathrm{~nm} ; 3.8 \mathrm{GJ} \mathrm{m}^{-2}\right)$ and vacuum up to $10^{-5} \mathrm{~Pa}$ (de Vera et al. 2004b), with survival rates ranging between 95 and $50 \%$, depending on the stressors applied. Additionally, $X$. elegans symbiont cells survived hypervelocity impacts up to $45 \mathrm{GPa}$ (Horneck et al. 2008). Based on the knowledge achieved in simulation experiments and 10 days LEO-exposure (BIOPAN 6) on the resistance of $X$. elegans to hostile conditions the next step was to test its ability to survive a long-term exposure to the combined conditions including the cosmic radiation of LEO-space. Consequently, it was chosen for LIFE to be exposed to real space and simulated Mars conditions for about 18 months (559 days). LIFE was intended to test the ability of the microorganisms to resist the space conditions of LEO and to assess the habitability of Mars' atmosphere for micro-organisms. Recent literature discusses the putative habitability of microniches on Mars (Westall 2013). It was one of the objectives of LIFE to study this possibility.

LIFE is the first experiment to expose lichens and - in parallel - its isolated $\mathrm{MB}$ for long-term duration ( $>1$ year) to LEO-space and to Mars-analogue conditions. The samples were exposed in the EXPOSE-E facility which was specifically designed for astrobiological research (Rabbow et al. 2012) and located on the European Columbus Module of the ISS.

The scientific objective of the present study is to analyse the viability of both $X$. elegans symbionts after LEO-space exposure and simulated Martian environmental conditions, to investigate differences between the exposure conditions, to characterize the extend and pattern of potential damages, to correlate the present results to previous studies and to assess the contribution of lichen-specific protective mechanisms to postexposure viability. Both, the space-exposed samples as well as the Mars simulation samples experienced three irradiation regimen at the ISS: one sub-set was exposed to the full spectrum of solar and cosmic irradiation, including ionizing radiation of different sources (refer to Berger et al. 2012), for a second sub-set the insolation was filtered down to $0.1 \%$, whereas a third sub-set was kept dark in the interior of the EXPOSE-E facility. A corresponding set of samples was exposed to conditions simulating as similar as possible the environmental conditions of the ISS exposure experiment, according to the data received from the EXPOSE-E facility at the ISS. The simulation was performed at the DLR in Cologne, herein referred to as Mission Ground Reference (MGR; Rabbow et al. 2012).

Preliminary results of LIFE were already presented (Onofri et al. 2012), while the present study focuses on the viability of $X$. elegans as an entire thallus and the effects of the long-term exposure. Post-flight viability of the lichen samples was examined by LIVE/DEAD analysis, using FUN-1 ${ }^{\circledR}$ staining and confocal laser-scanning microscopy (CLSM) analysis. The two-colour fluorescent cell-dye method allows the assessment of viability by membrane integrity and metabolic activity (Millard et al. 1997). In addition, chlorophyll $a$ fluorescence analyses confirmed the viability of the lichen's PB by providing insight to the photosynthetic capacity in its photosystem II (Lange et al. 1989; Schroeter et al. 1992).

The Lithopanspermia hypothesis (based on a proposal by Thomson, 1871) was revisited recently (Sancho et al. 2007; Stöffler et al. 2007; Horneck et al. 2008, 2010; de la Torre et al. 2010b) especially after several meteorites originating from Mars had been found and studied (Melosh 1984; Shuster \& Weiss 2005). The hypothesis implies the transfer of organisms on their host rock through space, and the seeding of life on a new planet, compelling the organisms to survive the impactdriven ejection, an interplanetary travel and an atmospheric re-entry after being captured by a planet's gravity. In the context of this hypothesis, several organisms were tested on their ability to survive shock pressures (Horneck et al. 2008), space conditions and a re-entry (de la Torre et al. 2010a; de Vera et al. 2010; Raggio et al. 2011; Onofri et al. 2012). Since the lichens $X$. elegans, Rhizocarpon geographicum and Circinaria gyrosa were part of this series of experiments (space exposure experiments LITHOPANSPERMIA, LICHENS I, LICHENS II and STONE at BIOPAN 4-6 on FOTON 2-3, 2002-2005; Sancho et al. 2007; de la Torre et al. 2010b), the present experiment on $X$. elegans contributes to the debate on the likelihood of lithopanspermia by revealing the long-term survival of symbiotic eukaryotes to the conditions of space exposure.

\section{Material and methods}

\section{Lichen samples}

$X$. elegans (Link) Th. Fr. (1860) is a cosmopolitan lichen colonizing various harsh habitats, including alpine (up to $7000 \mathrm{~m}$ a.s.l. in Himalaya), maritime and continental Antarctic inland sites (Øvstedal \& Lewis Smith, 2001). It is frequent on volcanic, silicate and limestone rock, at nitrophilic sites, and on anthropogenic substrata like concrete. X. elegans is usually exposed to high levels of insolation (Solhaug \& Gauslaa 1996, 2004; de Vera 2005). The thalli of $X$. elegans used in the present study were collected in June 2008 at Col du Sanetsch, Valais, Switzerland $\left(46^{\circ} 21^{\prime} 48^{\prime \prime} \mathrm{N}, 07^{\circ} 17^{\prime} 51^{\prime \prime} \mathrm{E}\right.$, at $2140 \mathrm{~m}$ a.s.1.) and adjacent collection sites (Zermatt, $46^{\circ} 00^{\prime} \mathrm{N}, 07^{\circ} 71^{\prime} \mathrm{E}$, at $1950 \mathrm{~m}$ a.s.1.), air-dried and frozen at $-20^{\circ} \mathrm{C}$ until further use. Samples originating from these collection sites were used in 
Table 1. Experimental parameters of the LIFE experiment. The irradiance at the sample site over the full spectrum are shown as average of the three distinct slots used for Xanthoria elegans samples (*) as calculated by Redshift (Redshift Protocol 2011). The irradiance for UVC (100-280 nm), UVB (280-315 nm), UVA (315-400 nm) and PAR (300-700 nm) are given in MJ m ${ }^{-2}$. Please mind the overlap of UVA and PAR. The last row shows the UV-fluence (200-400 nm) as calculated by Rabbow et al. (2012). Data are calculated for the middle of the sample site (Red Shift Protocol 2011).

\begin{tabular}{|c|c|c|c|c|c|}
\hline \multicolumn{3}{|l|}{ Space conditions } & \multicolumn{3}{|c|}{ Mars-analogue conditions } \\
\hline \multicolumn{3}{|l|}{$10^{-4}-10^{-7} \mathrm{~Pa}$} & \multicolumn{3}{|l|}{$10 \mathrm{hPa}$} \\
\hline \multicolumn{3}{|l|}{$208 \pm 8$ mGy } & \multicolumn{3}{|l|}{$215 \pm 16 \mathrm{mGy}$} \\
\hline \multicolumn{2}{|c|}{ Top layer, $\mathrm{MgF}_{2}$ window $(110 \mathrm{~nm}<\lambda>1 \mathrm{~mm})$} & \multirow{3}{*}{$\begin{array}{l}\text { Bottom layer } \\
\text { Dark exposure } \\
0 \mathrm{MJ} \mathrm{m}^{-2}\end{array}$} & \multicolumn{2}{|c|}{ Top layer, quartz window $(200 \mathrm{~nm}<\lambda>1 \mathrm{~mm})$} & Bottom layer \\
\hline Full insolation & $0.1 \%$ neutral density insolation & & Full insolation & $0.1 \%$ neutral density insolation & Dark exposure \\
\hline $4873 \mathrm{MJ} \mathrm{m}^{-2 *}$ & $6.30 \mathrm{MJ} \mathrm{m}^{-2 *}$ & & $4799 \mathrm{MJ} \mathrm{m}^{-2 *}$ & $5.90 \mathrm{MJ} \mathrm{m}^{-2 *}$ & $0 \mathrm{MJ} \mathrm{m}^{-2}$ \\
\hline UVC: 13.8 & UVC: 0.009 & UVC: - & UVC: 17.8 & UVC: 0.010 & UVC: - \\
\hline UVB: 41.2 & UVB: 0.040 & UVB: - & UVB: 46.8 & UVB: 0.037 & UVB: - \\
\hline UVA: 236 & UVA: 0.23 & UVA: - & UVA: 249 & UVA:0.21 & UVA: - \\
\hline PAR: 2185 & PAR: 2.55 & PAR: - & PAR: 2227 & PAR: 2.44 & PAR: - \\
\hline $634 \mathrm{MJ} \mathrm{m}^{-2}$ & $0.92 \mathrm{MJ} \mathrm{m}^{-2}$ & $0 \mathrm{MJ} \mathrm{m}^{-2}$ & $475 \mathrm{MJ} \mathrm{m}^{-2}$ & $0.63 \mathrm{MJ} \mathrm{m}^{-2}$ & $0 \mathrm{MJ} \mathrm{m}^{-2}$ \\
\hline
\end{tabular}

astrobiological studies before (de Vera et al. 2003, 2004a, b, 2007, 2008, 2010; Stöffler et al. 2007; Horneck et al. 2008).

\section{Methods}

\section{Sample handling}

Thalli were drilled off their stone substrata with a sample of diameter $7 \mathrm{~mm}$. A maximum quantum yield (Fv/Fm) measurement of photosystem II (mini-PAM, Walz, Germany) was performed before further processing to ensure the photosynthetic activity as a measure of the PB's vitality. Samples for the exposure experiment at the ISS and for the MGR were air-dried on orange silica gel and glued into the sample slots of the EXPOSE-E facility. The slots were sealed by an $\mathrm{MgF}_{2}$ or a quartz window with respect to the experimental conditions, for details refer to Rabbow et al. (2012).

After the exposure the ISS samples were removed from the EXPOSE-E facility at the DLR Cologne and mounted carefully in glass flasks separately, re-distributed to the investigators (including the MGR samples) and stored at $-20{ }^{\circ} \mathrm{C}$ until further investigation.

\section{Exposure parameters}

The LIFE applied six experimental conditions to overall 24 lichen and fungi samples (Table 1): 12 samples were exposed to space vacuum (tray 1) and 12 to a Mars-analogue atmosphere (tray 2). On the one hand tray 1 exposed its samples to $10^{-4}-10^{-7} \mathrm{~Pa}$ LEO space vacuum and provided them three intensities of solar radiation (dark, $0.1 \%$ neutral density filtered and full insolation with a wavelength range of $110 \mathrm{~nm} \lambda 1 \mathrm{~mm}$; samples covered with $\mathrm{MgF}_{2}$ windows). On the other hand, tray 2 supplied simulated Mars conditions with a $10^{3} \mathrm{~Pa}$ atmosphere (consisting of $95.3 \% \mathrm{CO}_{2}, 2.7 \% \mathrm{~N}_{2}, 1.6 \%$ Ar, $0.15 \% \mathrm{O}_{2}$ and $\sim 370 \mathrm{ppm}$ water vapour) and also three intensities of solar irradiation (dark, 0.1\% neutral density filtered and full insolation with a wavelength range of
$200 \mathrm{~nm} \lambda 1 \mathrm{~mm}$; samples covered by quartz windows). The reduced solar intensities were realized by additional neutral density filters, covering half of the sample slots of the trays' top layer and reducing the samples irradiation by the factor of 1000 while the dark-exposed samples were situated directly below the insolated top layer (Rabbow et al. 2012). Fully insolated samples accumulated an average of $4800 \mathrm{MJ} \mathrm{m}^{-2}$ photon energy input; $0.1 \%$ neutral density filtered samples accumulated $6.3 \mathrm{MJ} \mathrm{m}^{-2}$ photon energy in space vacuum or $5.9 \mathrm{MJ} \mathrm{m}^{-2}$ in Mars-analogue conditions (Table 1). Ionizing radiation was measured by passive detectors and its quality was evaluated and related to the sample positions (Berger et al. 2012; Dachev et al. 2012; Schuster et al. 2012). The samples experienced $208 \pm 8 \mathrm{mGy}$ (tray 1 ) and $215 \pm 16 \mathrm{mGy}$ (tray 2) of ionizing radiation from different sources (galactic cosmic rays, South Atlantic Anomaly, secondary radiation produced in the hardware, refer to Berger et al. 2012.) The temperature ranged from -21.7 to $+43^{\circ} \mathrm{C}$, with a one-time maximum of $61^{\circ} \mathrm{C}$ for a few hours (Rabbow et al. 2012). The EXPOSE-E facility was mounted outside the Columbus Module and its lids and valves were opened between 20th February 2008 and 20th August 2009, exposing the samples for 559 days. Owing to off-nominal events during the mission about $20 \%$ of the expected environmental data were lost. To assure a precise analysis of the samples' exposure conditions the solar irradiation was recalculated (RedShift Report 2011) leading to the average accumulated irradiance (as experienced by the samples) shown in Table 1.

\section{LIVE/DEAD staining}

The LIVE/DEAD staining was performed with the fluorescent dye FUN- $1^{\circledR}$ (Molecular Probes, Oregon, USA). The dye contains fluorophores excitable at $488 \mathrm{~nm}$ and changing their emission properties when metabolized. By up-taking the dye each cell achieves fluorescent labelling, detectable in the green channel (band-pass $505-550 \mathrm{~nm}$ ), while only metabolically 
active cells obtain a bright yellow to red emission with a vacuolar deposit of the dye (band-pass 575-615 nm, for details refer to Millard et al. 1997). For the quantification of active and inactive cells parts of the samples were wetted, crosssectioned into slices of 80-160 $\mu \mathrm{m}$ with a cryotome (ReichertJung, Germany) and immediately dyed on a microscope slide. The FUN-1 ${ }^{\circledR}$ solution was composed of $20 \mu \mathrm{M} \mathrm{FUN-1}{ }^{\circledR}$ in HEPES buffer ( $\mathrm{pH} 7 ; 1.0 \mu \mathrm{l}$ in $1 \mathrm{ml}$ ). The dying protocol followed the producer's manual, except an altered and prolonged incubation time with respect to the algal cell wall which was found to slow down the uptake of staining solution. The dyed samples were examined by CLSM (LSM 510 Meta, Zeiss, Germany), to verify the metabolic activity of the MB and the PB of $X$. elegans. For analysis, 6-15 pictures were taken for each sample with a 1.0-2.0 pinhole opening and amplifier values according to the fluorescence signal intensity (400-800; equal for the red and green channel). The measured emission for the picture composition was according to the emission maxima of the flourophores: green channel (signals of inactive cells) and red channel (signals of metabolically active cells). Besides these channels, PB cells were additionally marked by their chlorophyll auto-fluorescence for better discrimination, displayed in a blue channel (band-pass 660 $750 \mathrm{~nm})$.

The CLSM-pictures were analysed for metabolically active (interpreted as alive) and metabolically inactive (interpreted as dead) cells by manual counting, using an ImageJ counting tool (cell counter, ImageJ, W. Rasband, NIH, USA). Manual counting was necessary due to PB cell artefacts. These cells which showed bright yellow fluorescence active cells but no vacuolar deposits are misinterpreted by software-aided cell counters as active cells.

Owing to the expenses of space missions the sample quantity in space experiments is limited. Therefore not more than four replicates were available for the dark exposed and two replicates for the $0.1 \%$ neutral density filtered as well as for the fully insolated samples. The LIVE/DEAD staining procedure of each replicate included 7-29 technical replicates, gained by analysing and evaluating different sections and spots of each sample. The vital control samples were collected together with the ISS and MGR samples and stored at $-20^{\circ} \mathrm{C}$ until use.

\section{Chlorophyll a fluorescence}

Chlorophyll $a$ fluorescence was assessed by a Mini-PAM fluorimeter (Walz, Germany) according to Jensen (2002). The maximum quantum yield ( $\mathrm{Fv} / \mathrm{Fm})$ as a measure for the activity of the photosystem II is calculated as the ratio of variable fluorescence $(\mathrm{Fv})$ over maximum fluorescence $(\mathrm{Fm})$.

The analysis of the 16 ISS and the 16 MGR lichen samples followed three different protocols of sample re-activation prior to Mini-PAM measurement.

a) Standard protocol, applied directly before and after flight/MGR simulation: the lichen thalli were provided with $200 \mu \mathrm{l}$ sterile water and the chlorophyll $a$ fluorescence was measured $10 \mathrm{~min}$ afterwards. This is repeated four times to the maximum water supply of $800 \mu$ l. b) First re-activation protocol: $200 \mu \mathrm{l}$ water application twice and measurements after $0,1,2,3,24$ and $48 \mathrm{~h}$. The samples which had been exposed in Mars-analogue conditions were additionally measured after 72 and $96 \mathrm{~h}$.

c) Second re-activation protocol: for the samples 100 and 116 (space vacuum conditions) the first re-activation was repeated after a day of air-drying, in order to emulate the wet/dry cycle of lichens in their natural environment. Again the measurements took place after $0,1,2,3,24,48,72$ and $96 \mathrm{~h}$.

\section{Statistical analyses}

Testing the data for significant difference was done with GraphPad InStat 3 software, applying an unpaired $t$-test with Welch correction, ANOVA with parametric or non-parametric testing or Mann-Whitney test with two-tailed $P$ value. Correlation coefficient and standard deviations were calculated with MS excel 2010.

\section{Abbreviations (exposure parameters)}

Space: samples were exposed in space vacuum conditions; Mars ac: samples were exposed in Mars-analogue conditions; full ins.: samples experienced full solar irradiation; $0.1 \%$ ins.: solar irradiation of the samples was reduced to $0.1 \%$ of the full insolation (neutral density filter); dark exp.: samples experienced no direct insolation.

\section{Results}

After the exposure experiment both, the ISS and MGR samples appeared unaltered in colour and structure in the first visual inspections compared with untreated control samples. The viability of the lichen samples was analysed by different methods, with regard to the different cell types (PB and MB) and the structure of the lichen thallus. The LIVE/DEAD staining with FUN- $1{ }^{\circledR}$ was well feasible for the hyphal cells of the MB and appropriate for the coccal green algal PB. Additionally, photosynthetic activity of the PB was analysed by chlorophyll $a$ fluorescence and related to the LIVE/DEAD staining results.

\section{LIVE/DEAD staining ( FUN $\left.-1^{\circledR} / C L S M\right)$}

In all samples metabolically active $\mathrm{MB}$ and $\mathrm{PB}$ cells were observed when incubated with FUN- $1^{\circledR}$. The samples displayed a reproducible staining pattern in CLSM analyses. The space exposed samples (ISS) and the samples exposed to simulated space conditions (MGR) as well as the control samples (stored at $-20^{\circ} \mathrm{C}$, dark), showed equal reactions regarding up-take, and metabolization of FUN-1 ${ }^{\circledR}$ and fluorescence signal quality. Figures 1 and 2 show the number of metabolically active $\mathrm{PB}$ and $\mathrm{MB}$ cells, respectively, displayed as percentage of total cells counted and according to the six different experimental conditions on the ISS and in the MGR. The number of replicates is given in Table 2.

The percentage rate mean values of active $\mathrm{PB}$ cells ranged from $43 \%$ (MGR $0.1 \%$ ins. Mars ac and MGR full ins. Mars ac) to $83 \%$ (ISS full ins. space) and for active MB cells 


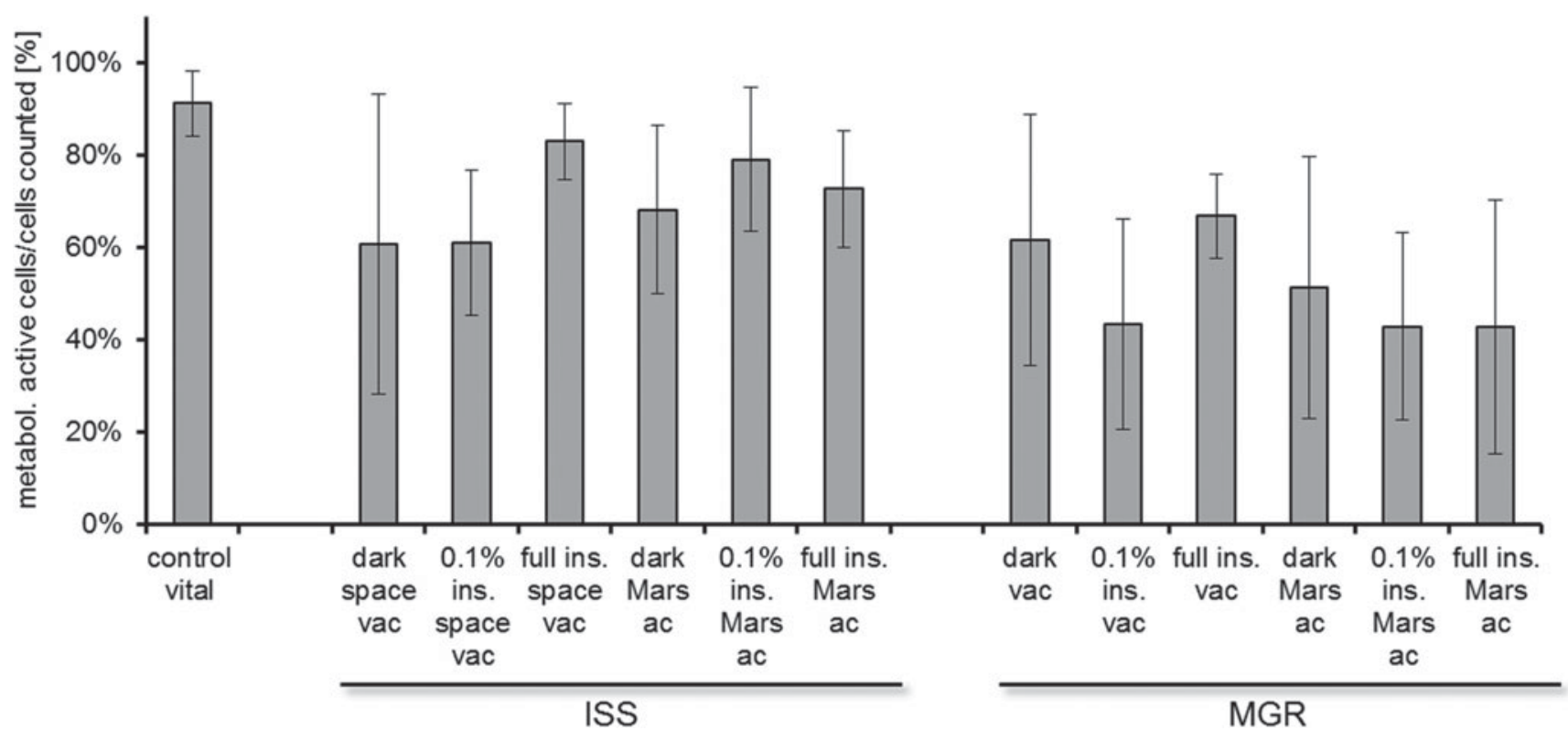

Fig. 1. LIVE/DEAD staining: metabolically active photobiont cells as percentage of cells counted, mean viability values for each sample position/ experimental condition in EXPOSE-E plus untreated control group.

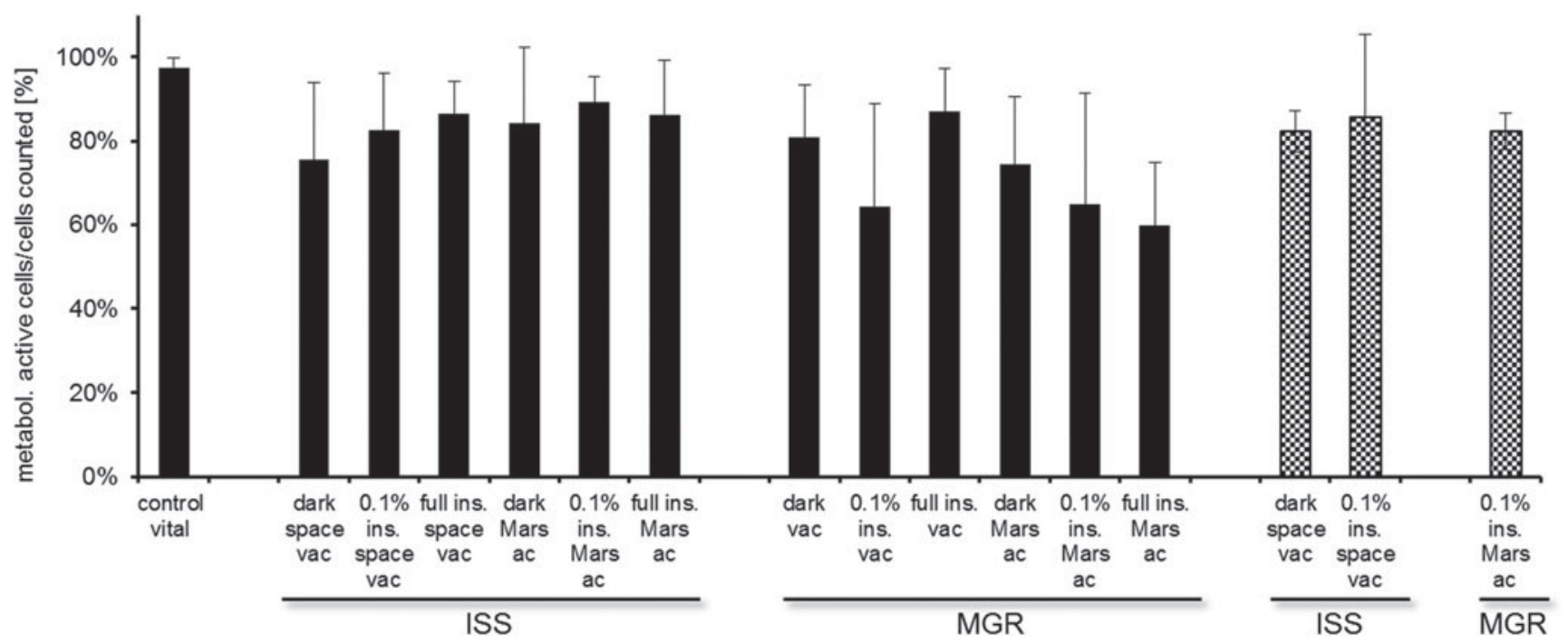

Fig. 2. LIVE/DEAD staining: metabolically active mycobiont (MB) cells as percentage of cells counted, mean viability values for each sample position/experimental condition in EXPOSE-E plus untreated control group. Squared columns show isolated non-lichenized MB samples.

from $60 \%$ (MGR full ins. Mars ac) to $89 \%$ (ISS $0.1 \%$ ins. Mars ac).

MB hyphae appeared to be more resistant towards extreme conditions compared with PB cells which can be recognized to be deformed or collapsed in some sections. The space exposed samples showed a higher survival rate of clustered PB cells in the anatomical centre of the lichen thallus or below thick cortical structures as well as apothecia (Fig. 3). The samples revealed a remarkably high number of metabolically active cells with over-all mean values of $61 \%$ for active PB cells and of $78 \%$ for MB cells. The MB always showed higher viability percentages than the $\mathrm{PB}$, while the loss of viability of both symbionts is correlated to each other under all experimental conditions applied. Samples of the isolated non-lichenized MB were tested with the $0.1 \%$ neutral density insolation filtering and as dark exposed samples. A mean value of $83 \%$ metabolically active hyphae of the mycelium (non-lichenized MB) has been detected, which is comparable to the percentage rate mean values of active $\mathrm{MB}$ cells in the entire lichen thallus (mean value of $79 \%$ ).

In order to evaluate the specific effect of the experimental conditions applied, the viability rates of $\mathrm{PB}$, lichenized MB and non-lichenized MB were correlated to the different experimental conditions. The combined ISS and MGR viability rates of PB and MB in dependency to the three intensities of solar irradiation are illustrated in Fig. 4. There is no significant 
Table 2. Cell viability: the results obtained from the EXPOSE-E samples sorted by the six different conditions applied on ISS and during MGR. Legend: space: samples experienced space vacuum; Mars ac: samples experienced Mars analogue conditions; full ins.: full insolation; $0.1 \%$ ins.: $0.1 \%$ neutral density filtered insolation; dark exp.: samples experienced no direct irradiation MV: mean value of vital cells as percentage of total cells counted, uses mean values of technical replicates; SD: standard deviation; $\mathrm{n}_{\text {tech }}$, $\mathrm{n}_{\text {biol: }}$ : number of technical and biological replicates; control vital: untreated Xanthoria elegans control samples, stored at $-20^{\circ} \mathrm{C}$.

\begin{tabular}{|c|c|c|c|c|c|c|c|c|}
\hline & \multicolumn{4}{|l|}{ ISS } & \multicolumn{4}{|l|}{ MGR } \\
\hline & MV in $\%$ & SD & $n_{\text {tech }}$ & $n_{\text {biol }}$ & MV in $\%$ & SD & $n_{\text {tech }}$ & $n_{\text {biol }}$ \\
\hline \multicolumn{9}{|l|}{ Photobionts } \\
\hline Control vital & 91.3 & 7.0 & 19 & 6 & 91.3 & 7.0 & 19 & 6 \\
\hline Dark exp., space & 60.8 & 32.5 & 22 & 4 & 61.7 & 27.2 & 23 & 4 \\
\hline $0.1 \%$ ins., space & 61.2 & 15.8 & 7 & 2 & 43.5 & 22.9 & 14 & 2 \\
\hline Full ins., space & 83.1 & 8.2 & 14 & 2 & 66.8 & 9.2 & 10 & 2 \\
\hline Dark exp., Mars ac & 68.3 & 18.2 & 27 & 4 & 51.5 & 28.4 & 27 & 4 \\
\hline $0.1 \%$ ins., Mars ac & 79.1 & 15.5 & 13 & 2 & 43.0 & 20.2 & 7 & 1 \\
\hline Full ins., Mars ac & 72.7 & 12.7 & 20 & 2 & 42.9 & 27.6 & 13 & 2 \\
\hline \multicolumn{9}{|l|}{ Mycobionts } \\
\hline Control vital & 97.4 & 2.3 & 14 & 6 & 97.4 & 2.3 & 14 & 6 \\
\hline Dark exp., space & 75.7 & 18.4 & 29 & 4 & 80.8 & 12.6 & 20 & 4 \\
\hline $0.1 \%$ ins., space & 82.7 & 13.5 & 8 & 2 & 64.2 & 24.8 & 13 & 2 \\
\hline Full ins., space & 86.6 & 7.7 & 14 & 2 & 87.1 & 10.3 & 10 & 2 \\
\hline Dark exp., Mars ac & 84.3 & 18.0 & 23 & 4 & 74.3 & 16.4 & 29 & 4 \\
\hline $0.1 \%$ ins., Mars ac & 89.2 & 6.2 & 10 & 2 & 64.9 & 26.6 & 7 & 1 \\
\hline Full ins., Mars ac & 86.2 & 13.1 & 16 & 2 & 59.8 & 15.2 & 15 & 2 \\
\hline
\end{tabular}

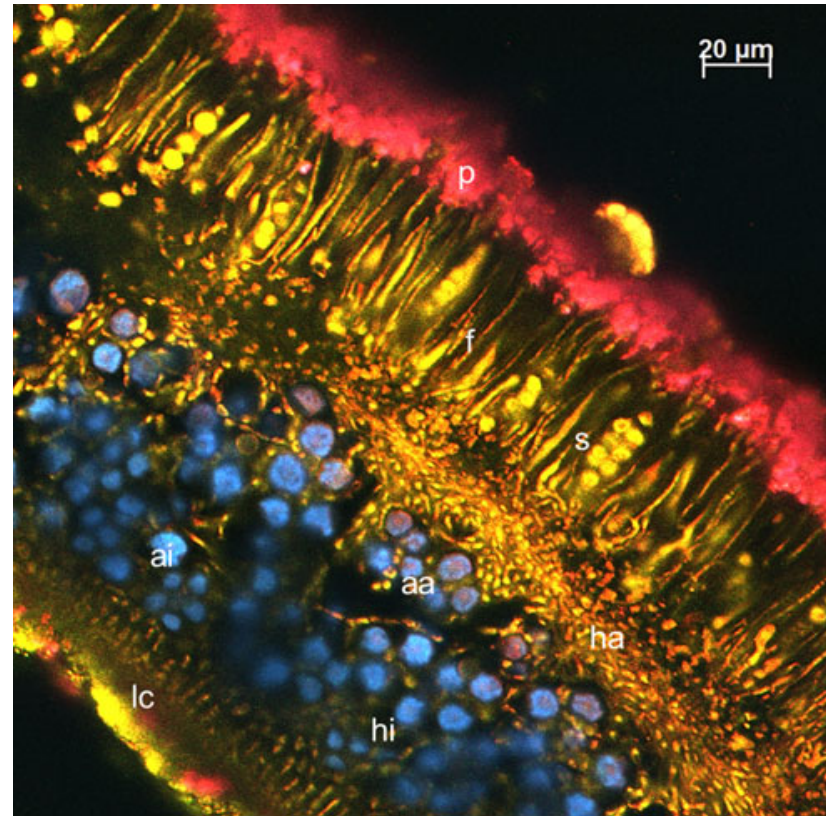

Fig. 3. Xanthoria elegans (cross-section) stained with FUN-1 ${ }^{\circledR}$, documented by CLSM, ISS LIFE sample (full insolation space vacuum). p: parietin encrusted upper cortex layer; f: apothecia (fruiting body) with s: spores; fungal hyphae (MB): ha: active (vital) hyphae, hi: inactive hyphae; algal cells (PB): aa: active (vital) algae, ai: inactive algae; lc: lower cortex.

difference in the viability rates in reference to the insolation conditions. The three orders of magnitude higher energy input to unfiltered ISS or MGR samples - compared to the $0.1 \%$ neutral density filtered samples - did not elicit a significant change of the survival rates. The dark exposed samples did not show higher viability rates while the untreated control samples showed a significantly higher amount of metabolically active cells for both MB and PB.

Additionally, the results of ISS and MGR dark-exposed samples were assembled to depict the differences between Mars-analogue and space vacuum conditions (Fig. 5). No significant differences were observed. All MGR samples showed a clear decrease in metabolic activity, compared with the control and but also compared with the ISS samples, with a minimum of $36 \% \mathrm{~PB}$ viability in one MGR sample. These results coincide with the results of the chlorophyll $a$ fluorescence analyses (see below), indicating a possible negative effect of MGR-exposure on viability.

The ISS lichen samples revealed a minor decrease in activity for the cells exposed in Mars-analogue conditions. The mean values of the viability rates of the MB showed a $5.5 \%$ higher viability under Mars-analogue conditions, compared with the space vacuum MB samples. The difference is significant (twotailed $P$ value 0.0212 , Mann-Whitney test). The difference of the PB viability rates resulted in an insignificant increase of $4 \%$ in favour of the Mars-analogue atmosphere. The MGR vacuum samples showed an elevated level of metabolic activity compared with those cells exposed under Mars-analogue conditions. The MB mean viability rate was $7.2 \%$ higher and the $\mathrm{PB}$ showed even $9.5 \%$ higher viability in the MGR vacuum, compared with the MGR Mars-analogue atmosphere. The different amount of metabolically active cells between ISS and MGR samples was tested for its significance (Mann-Whitney test). The difference is significant for the MB (two-tailed $P$ value: 0.0152 ) and very significant for the PB (two-tailed $P$ value: 0.0043 ). 


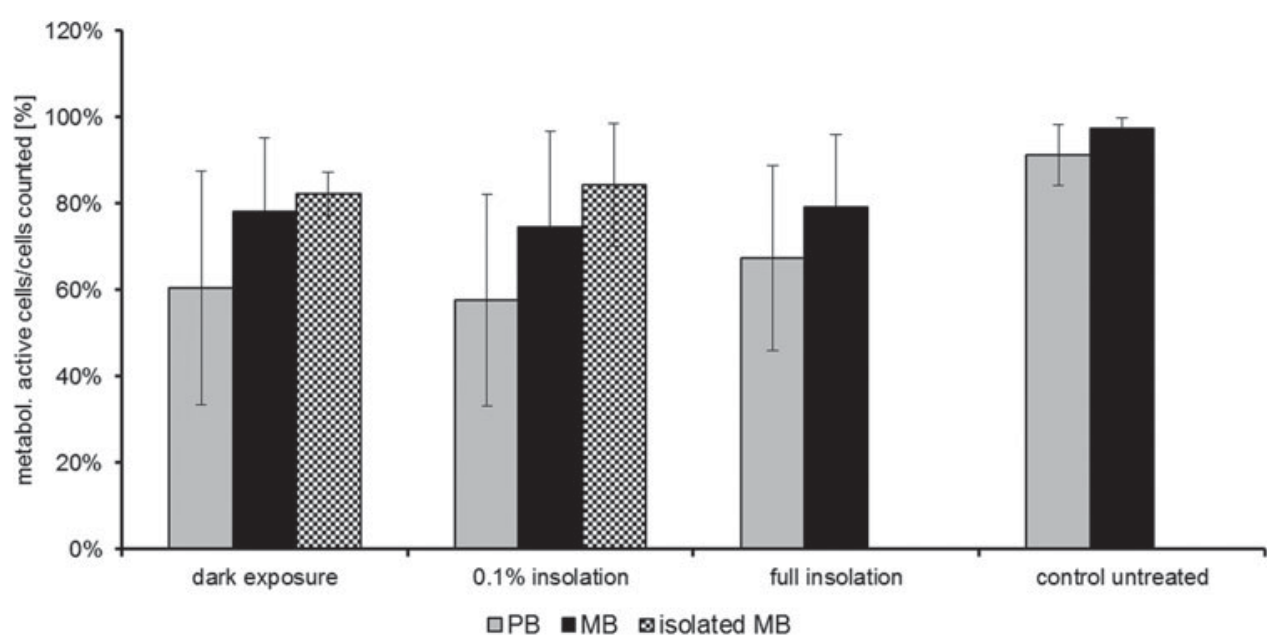

Fig. 4. Viability of ISS and MGR samples related to received photon/EM fluence (110/200 nm $\lambda 1 \mathrm{~mm})$; viability assessed by Fun- $1^{\circledR}$ LIVE/DEAD staining and analysed by CLSM. No significant differences occurred related to the different insolation applied.

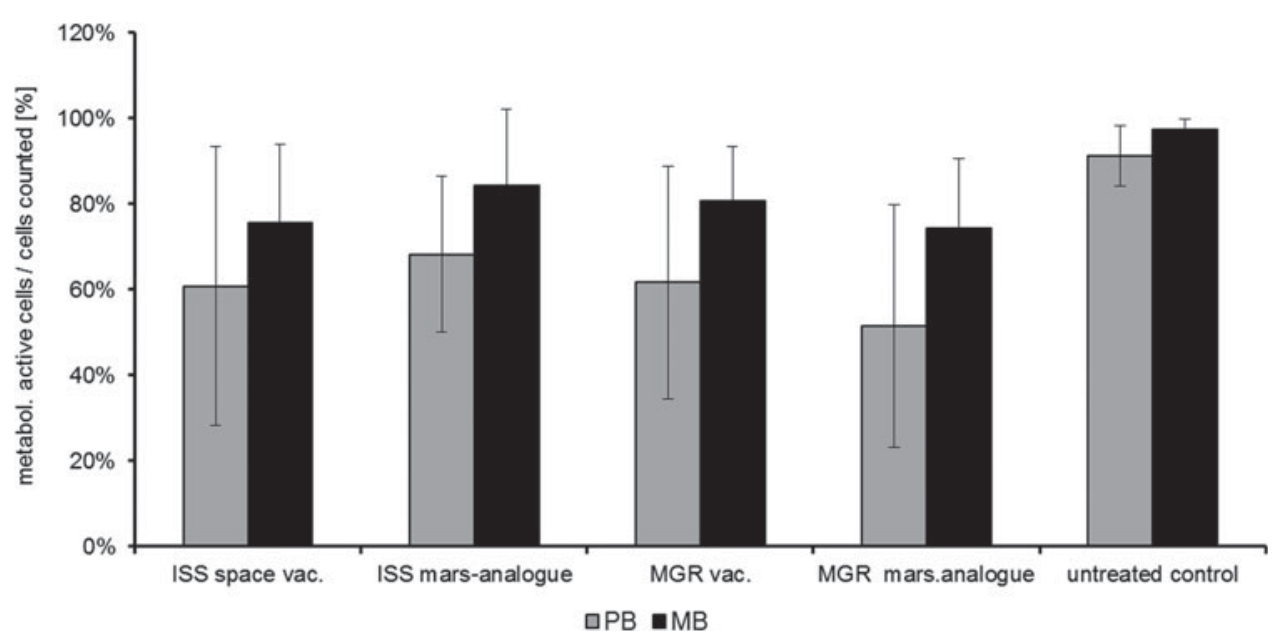

Fig. 5. Mars-analogue atmosphere versus space vacuum conditions: mean viability rates of photobiont cells and mycobiont hyphae in $X$. elegans with reference to the atmospheric conditions; dark-exposed samples.

DNA damage and cell decay caused by ionizing radiation of different sources has not been quantified yet. The measured accumulated doses of ionizing radiation (200-231 mGy) were mainly due to protons of the radiation belt which hit the ISS when it passed through the South Atlantic Anomaly (Dachev et al. 2012). The doses are not likely to explain viability loss of samples, because $50 \%$ of irradiated lichen algae survived doses of 90-480 Gy (10-54 kR) while fungal hyphae seemed even less sensitive to radiation (Gannutz 1972). The results of the LIVE/DEAD analyses indicate that after 1.5 year exposure in LEO a total average of $71 \%$ of the PB and $84 \%$ of the MB cells revealed metabolic activity. A less pronounced decrease of viability of MB and PB cells occurred under ISS Marsanalogue conditions. This is confirmed by a higher PS II activity of the PB exposed in ISS Mars-analogue conditions according to chlorophyll $a$ fluorescence measurements as presented below.

\section{Chlorophyll a fluorescence}

Preliminary results of chlorophyll $a$ fluorescence measurements on the post-flight viability of $X$. elegans $\mathrm{PB}$ have been presented before by Onofri et al. (2012) including also results of the lichen $R$. geographicum. Complementary, the following analysis focuses on the correlation between chlorophyll $a$ fluorescence (as a marker of the PB's vitality) and the previously described results of the LIVE/DEAD analyses with regard to the experimental conditions applied and the characteristics of $X$. elegans.

The lichen samples (ISS and MGR) were measured prior to the exposure (pre-flight) and after their return (post-flight) according to a standardized measuring protocol. The mean values of the natural pre-flight values and initial post-flight measurements are given in Fig. 6. The highest post-flight Fv/Fm (= maximum quantum yield of photosystem II) value 


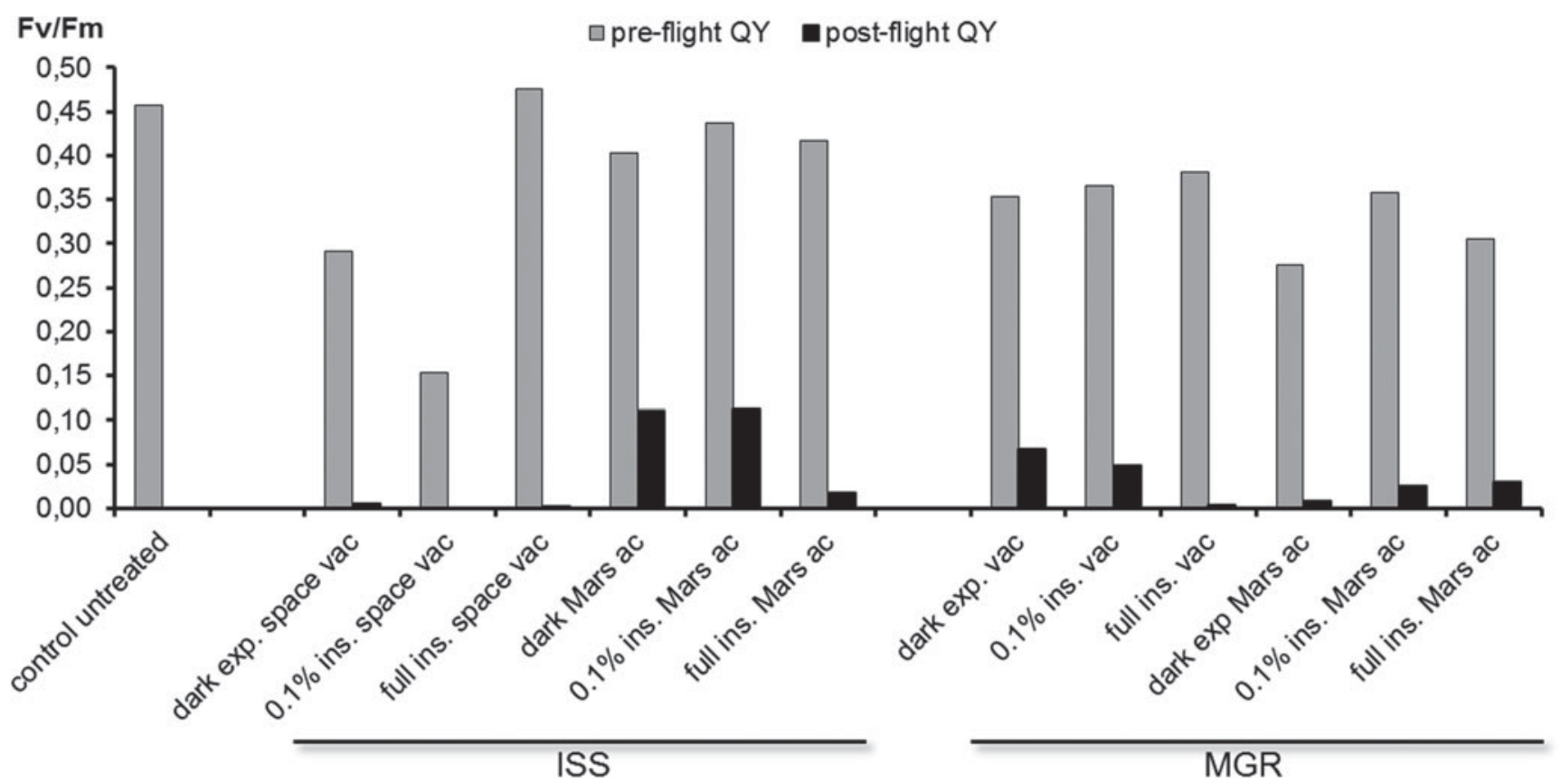

Fig. 6. Chlorophyll $a$ fluorescence data of pre- and post-flight photosynthetic activity (Fv/Fm) as measured after standard protocol for each sample (ISS and MGR). The short wetting time was not sufficient for the strongly desiccated samples.

which was achieved by a single sample was 0.238 (MGR dark exp. space), followed by 0.148 and 0.129 (both ISS dark exp. Mars ac) representing $37-40 \%$ of their pre-flight $\mathrm{Fv} / \mathrm{Fm}$ values. Most of the samples showed none or just a minimum of activity, defined as $\mathrm{Fv} / \mathrm{Fm}<0.1$ in the initial post-flight measurement.

After the measurements described above, an additional reactivation was carried out two times. The first re-activation procedure enabled the strongly desiccated lichen (due to the effect of long-term space vacuum) to take up the allocated water and re-activate in a time range of 48 and $96 \mathrm{~h}$. In this experiment, the number of examined samples was reduced, due to the finite sample quantity and in order to conserve sample material for different experiments to follow (e.g. DNA analyses, anatomical studies). The eight samples selected (four ISS; four MGR) showed different effects in response to the prolonged water availability. After $48 \mathrm{~h}$ of re-activation, four of the analysed samples indicated post-flight photosynthetic activity of the PB. Two out of these four samples revealed high Fv/Fm values (Fig. 7(a): 0.543: ISS dark exp. Mars ac; 0.621: ISS $0.1 \%$ ins. Mars ac) while two samples gave values indicating moderate photosynthetic activity (Fig. 7(a): 0.392: ISS dark exp. space and Fig. 7(b): 0.335: MGR 0.1\% ins. Mars ac). The other four samples showed very low $\mathrm{Fv} / \mathrm{Fm}$ values (Fig. 7(a): 0.106: ISS full ins. space; Fig. 7(b): 0.105: MGR dark exp. space, 0.000: MGR full ins. space and 0.039: MGR dark exp. Mars ac). Three out of the four samples which were exposed under Mars-analogue conditions showed increased Fv/Fm values after $96 \mathrm{~h}$ of re-activation (Fig. 7(a): 0.602: ISS dark exp. Mars ac; 0.641: ISS 0.1\% ins. Mars ac; Fig. 7(b): 0.444: MGR $0.1 \%$ ins. Mars ac). One of the MGR samples revealed no photosynthetic activity after the prolonged reactivation period (Fig. 7(b): MGR dark exp. Mars ac).
The second re-activation procedure (Figs. 7(c): ISS samples; 7(d): MGR samples), following the same protocol as used in the first re-activation, was performed after the four space vacuum exposed samples of the first re-activation (ISS and MGR) had been desiccated again, because cycles of drying and wetting mimic the lichens' poikilohydric lifestyle. The Fv/Fm value increased by $56 \%$ for the ISS dark exp. sample. For other space vaccum samples the $\mathrm{Fv} / \mathrm{Fm}$ values increased but were still remained on a low level (Fig. 7(c): 0.234: ISS full ins.; Fig. 7(d): 0.207: MGR dark exp.) after $96 \mathrm{~h}$ of re-activation. The MGR full ins. revealed no residual photosynthetic activity (Fig. 7(d)).

Four samples can be regarded as viable, according to the chlorophyll $a$ fluorescence measurement, two samples showed reduced activity, and only two samples failed the re-activation, both of MGR. In six tests, the prolonged re-activation procedure resulted in higher $\mathrm{Fv} / \mathrm{Fm}$ values, compared with the short-term activation pre- and post-flight measurements.

For three of the samples, there was a clear correlation between the re-activation procedure (wetting time, interrupted by desiccation) and a gain of measureable photosynthetic activity (Fig. 8). Thus, it is concluded that a prolonged time of re-activation procedure of multiple water supply and intermediate desiccation results in re-activation of photosynthetic activity, even for samples appearing inactive in the initial postflight measurement. Compared with the ISS samples the MGR samples always showed reduced Fv/Fm values.

\section{Correlation of viability data by LIVE/DEAD staining and chlorophyll a fluorescence}

1. Compared with the ISS samples the MGR samples showed reduced viability in LIVE/DEAD staining and in PS II activity. 
$\mathrm{Fv} / \mathrm{Fm}$

ISS: $1^{\text {st }}$ reactivation

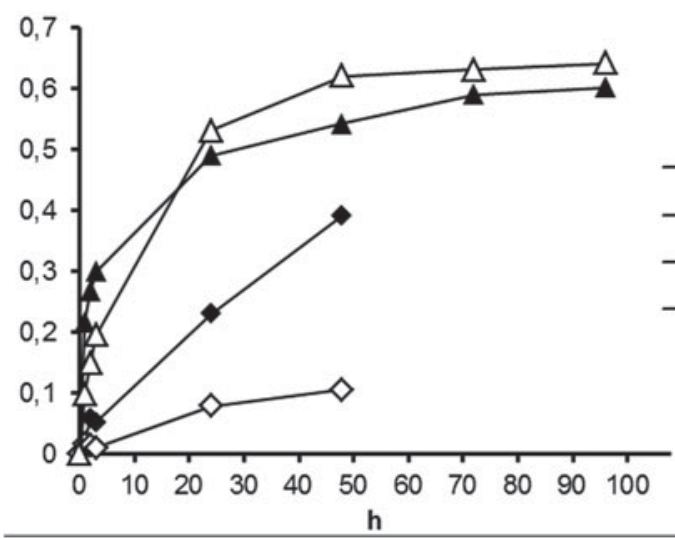

Fv/Fm ISS (vacuum): $2^{\text {nd }}$ reactivation

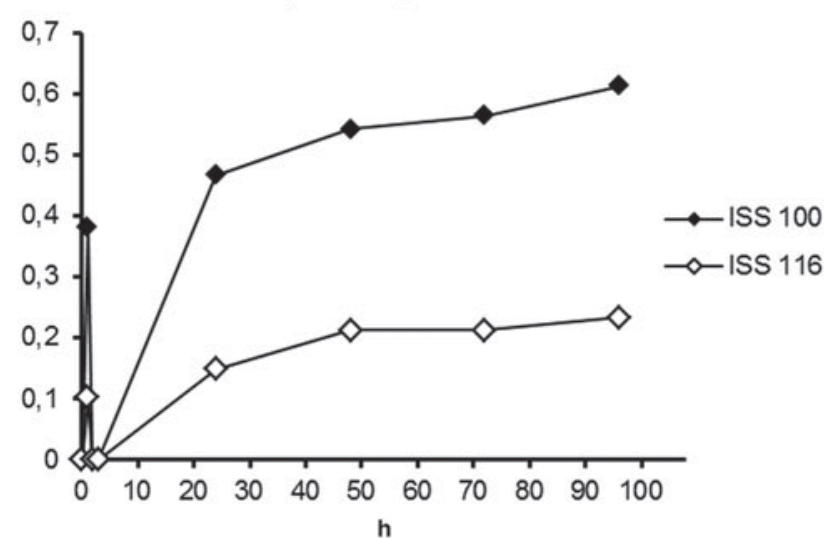

a

Fv/Fm

MGR: $1^{\text {st }}$ reactivation

b

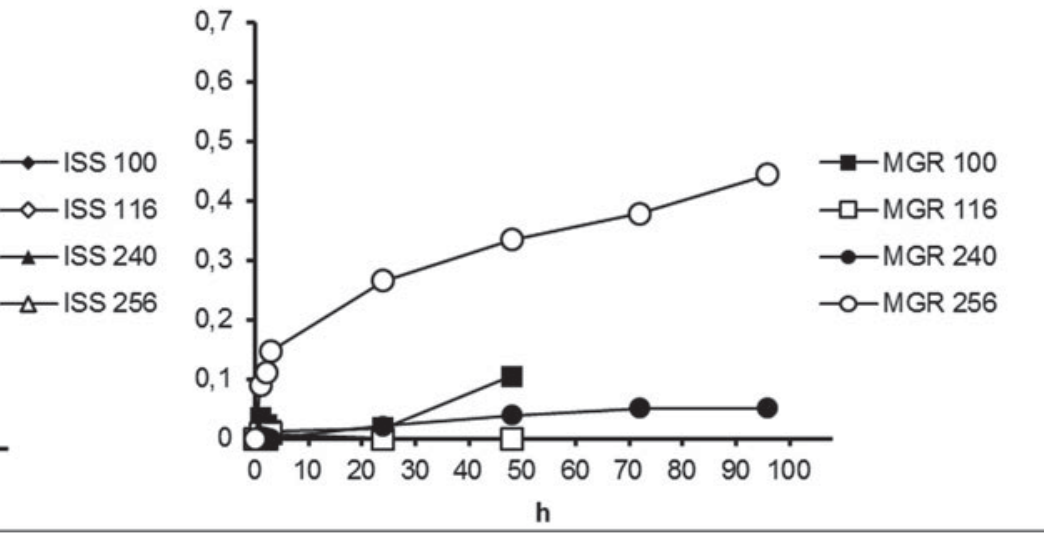

c Fv/Fm MGR (vacuum): $2^{\text {nd }}$ reactivation $\quad \mathrm{d}$

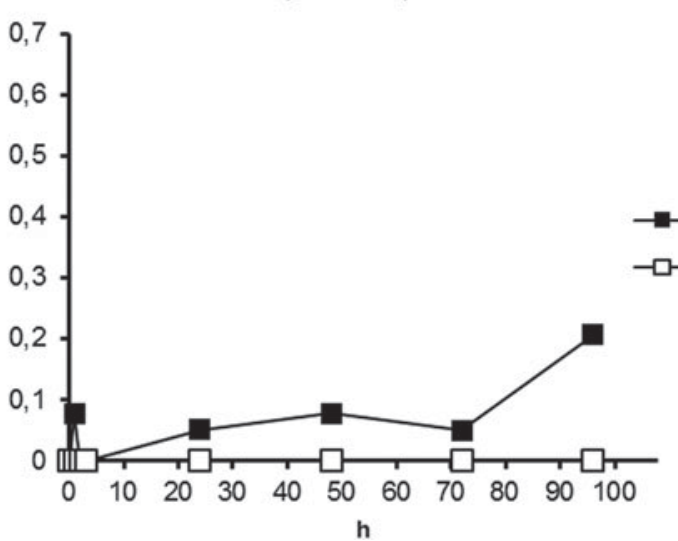

Fig. 7. Photosynthetic activity (as maximum quantum yield, Fv/Fm) in Xanthoria elegans after LIFE exposure according to the prolonged reactivation protocols (a) ISS samples, first re-activation; space vacuum: dark-exposed (100), full insolation (116); Mars-analogue conditions: dark exposed (240), full insolation (256). (b) MGR samples, conditions (simulated) and sample numbers as in (a). (c) ISS samples, second re-activation of the space vacuum samples, dark exposed (100), full insolation (116). (d) MGR samples, second re-activation of the vacuum samples, dark exposed (100), full insolation (120).

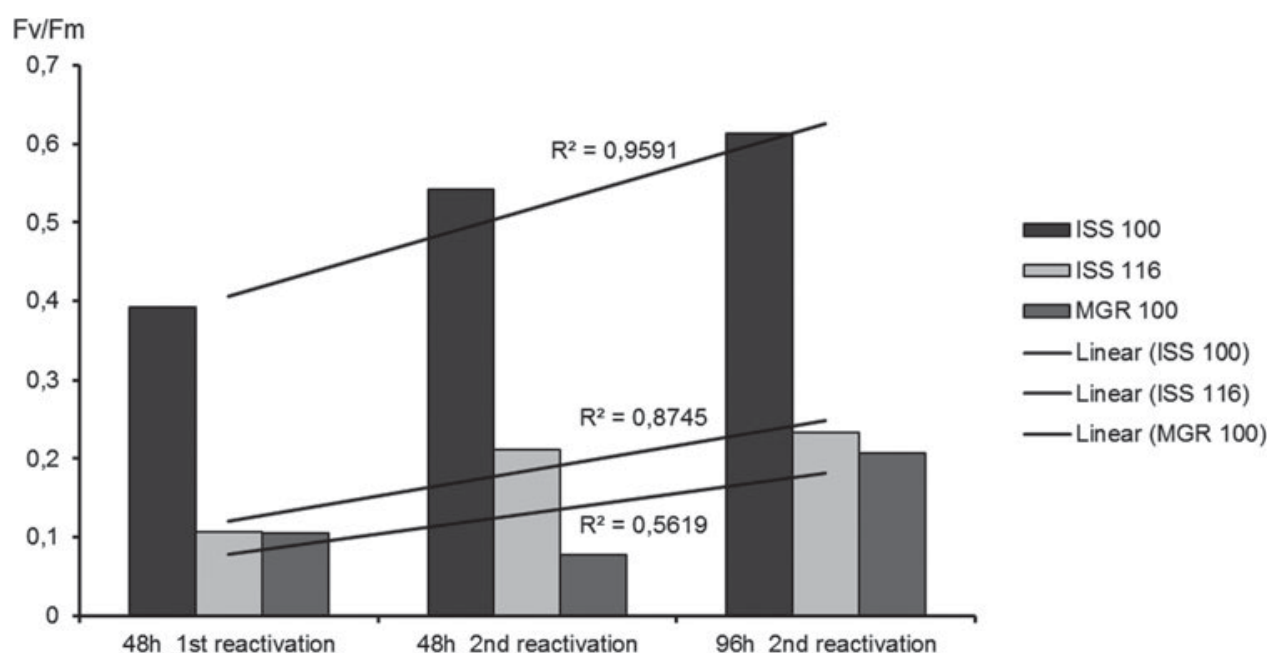

Fig. 8. First and second re-activation of the ISS and MGR space vacuum samples: samples show positive linear correlations of reactivation time (h) and maximum quantum yield of PS II (Fv/Fm). Samples dried between the re-activation (wetting) in ambient conditions. 


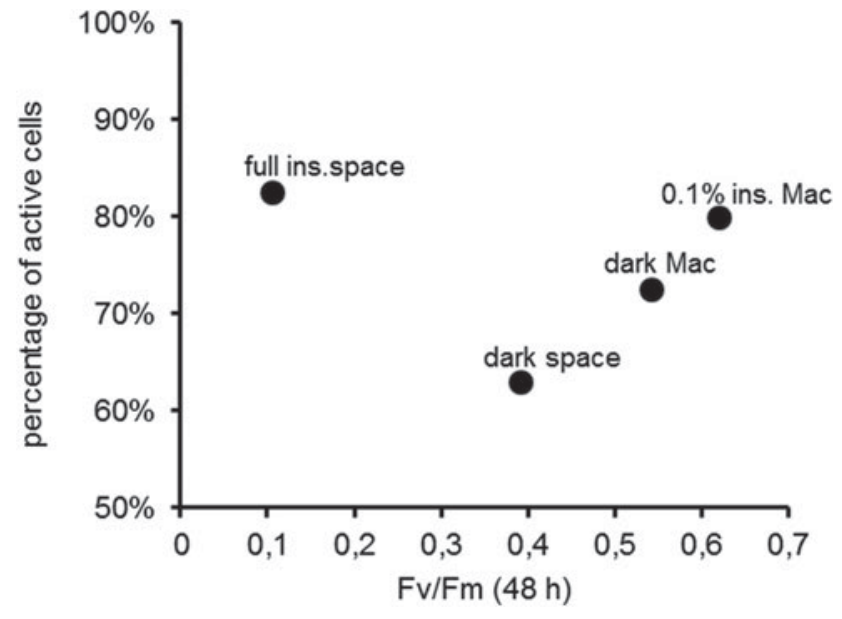

Fig. 9. ISS samples: correlation between the Fv/Fm values (chlorophyll $a$ fluorescence) and cell viability assessed by LIVE/ DEAD staining. The viability of the analysed samples is correlated for the both methods, except the space vacuum full insolation sample, which showed high metabolic activity combined with lower Fv/Fm values than samples of filtered insolation or dark exposure. full ins., full insolation; $0.1 \%$ ins., $0.1 \%$ insolation; dark, dark exposure; space, space vacuum; Mac, Mars-analogue conditions.

2. A prolonged re-activation procedure is mandatory to properly re-activate the photosynthetic activity. This might be due to the intense desiccation in space vacuum and the time which might be needed for cellular repair mechanisms.

3. The duration of the re-activation and the maximum quantum yield of photosystem II $(\mathrm{Fv} / \mathrm{Fm})$ are correlated (Fig. 8).

4. The ISS samples exposed under Mars-analogue conditions revealed higher viability rates, compared with the ISS space vacuum samples (Figs. 5 and 7(a)), and needed less reactivation time (Fig. 7(a)). According to the ISS sample results Mars-analogue conditions provided improved survival conditions for the anabiotic lichens.

5. The measured Fv/Fm values of the ISS samples can be correlated to the amount of PB cells detected as metabolically active in the LIVE/DEAD staining for three out of four ISS samples (Fig. 9: four samples after $48 \mathrm{~h}$ of first re-activation). Higher Fv/Fm values correlated to higher $\mathrm{PB}$ vitality rates in the LIVE/DEAD staining analysis. Only one sample (ISS full ins. space) showed a low Fv/Fm (maximum quantum yield) value, but high metabolic activity of $\mathrm{PB}$ cells in LIVE/DEAD staining analysis, indicating that the photosynthetic activity can be reduced without a loss of the overall metabolic activity in the PB cells.

\section{Discussion}

To fathom the limits and limitations of life it is fundamental to conduct real space and Mars-analogue exposure experiments. LIFE tested the potential of lichens' survival under non-terrestrial conditions, as intense solar radiation, lack of atmospheric shielding, LEO-cosmic-radiation, vacuum which causes extreme desiccation, different atmosphere and a temperature-regime including rapid freeze/thaw cycling (Berger et al. 2012; Rabbow et al. 2012). The Mars-analogue conditions compartment of LIFE was intended to assess the possibility of microbial life (extinct or recent) in putative micro-niches on Mars.

According to the LIVE/DEAD viability analyses, the symbionts of $X$. elegans achieved remarkable high viability rates with a total average of $71 \%(\mathrm{~PB})$ and $84 \%(\mathrm{MB})$ after 18 months of space exposure on the ISS. These results were substantiated by the chlorophyll $a$ fluorescence analysis, illustrating a profound recovery of photosynthetic activity if properly re-activated. Besides these data obtained from LIVE/ DEAD and chlorophyll $a$ fluorescence analyses, $X$. elegans also revealed its remarkable post-flight viability and the capability of continuous proliferation in culture-based assays of the PB (Brandt et al. in preparation).

The post-flight viability of $X$. elegans is not reached by other organisms exposed in LIFE, including the lichen $R$. geographicum which re-gained not more than $2.5 \pm 1.4 \%$ of its preflight PS II activity, compared with $75 \%$ for some $X$. elegans samples (ISS dark exp. space; Onofri et al. 2012). Additionally, Antarctic sandstone samples which were colonized by cryptoendolithic micro-organisms (fungi, algae and yeasts among others) and exposed in parallel to both lichens, produced three fungal colonies from the dark exposed space vacuum sample and one green algal colony from the $0.1 \%$ insolated Marsanalogue conditions sample (Scalzi et al. 2012), although qPCR propidium monoazide assays indicated quite high rates of non-damaged cryptoendolithic fungal cells (Onofri et al. 2012).

The high survival rates of $X$. elegans might be caused by its particular adaptation properties. Unlike the cryptoendolithic organisms, $X$. elegans does not depend on shielding by rock, but is well adapted to exposed habitats (Nybakken et al. 2004; de Vera et al. 2008) characterized by high insolation (Nybakken et al. 2004), extreme temperatures and occasionally higher altitudes. The adaptations of the lichens to the environmental conditions in their original habitat comprise different strategies of stress avoidance (Kappen 2000; Meeßen et al. 2013b) and damage repair (Eker et al. 1994; Petersen et al. 1999; Buffoni Hall et al. 2003). However, this study focuses on the anhydrobiotic (anabiotic) state of desiccated lichens and on the potential to avoid damage caused by insolation with wavelengths $>110 \mathrm{~nm}$ (space vacuum) and >200 nm (Marsanalogue conditions), respectively.

LIFE/DEAD staining and chlorophyll $a$ fluorescence analyses form a comparable pattern of both vital MB and $\mathrm{PB}$ in the samples examined. The only exception is the PB of the ISS fully insolated space vacuum sample which failed to reach its pre-flight $\mathrm{Fv} / \mathrm{Fm}$ values in the chlorophyll $a$ fluorescence measurements, revealing a deficit in photosynthetic activity, although the LIVE/DEAD staining analysis indicated a high average quantity of metabolically active cells (about $83 \%$ ). The chlorophyll $a$ fluorescence data of $X$. elegans 
(ISS samples) correspond to the results presented by Onofri et al. (2012), indicating a full recovery (about 99\%) of the photosynthetic activity for all ISS samples, except the space vacuum samples exposed to full solar irradiation which reached only $45 \%$ of the pre-flight $\mathrm{Fv} / \mathrm{Fm}$ values. This is consistent with the present study indicating $50 \%$ of the pre-flight $\mathrm{Fv} / \mathrm{Fm}$ value for this sample. The viability rates of each sample's $\mathrm{PB}$ and MB appear to be coupled to each other, this is confirmed by a linear correlation between the viability rates of $\mathrm{MB}$ and $\mathrm{PB}$ (coefficient of correlation is 0.95). $\mathrm{PB}$ and $\mathrm{MB}$ reacted likewise to the environmental condition applied with a proportionally higher rate of damage in the PB.

Owing to the narrow sample number available in LIFE, and its subsequent partition on various analytical methods, the influence of individual sample characteristics might be considered. Intersample variety might also be caused by different pre-flight vitality of individual lichen samples as well as by slightly differing thallus orientation during exposure or individual thallus structures (Meeßen et al. 2013b).

\section{Anhydrobiosis: vacuum and freezing}

Their poikilohydric nature enables lichens to endure unfavourable environmental conditions in a state of anhydrobiosis, 'latent life', mainly induced by desiccation (Crowe et al. 1992). Anhydrobiosis provides enormous desiccation tolerance (Hoekstra et al. 2001; Schlensog et al. 2003; Rebecchi et al. 2007) and supports the importance of the poikilohydry as a fundamental life strategy of the lichen symbiosis in response to hostile conditions (Kranner et al. 2008). Although the non-lichenized PB is discussed to be more sensitive to intense insolation and desiccation than the MB (de la Torre et al. 2002; de Vera et al. 2008; de Vera \& Ott 2010; de Vera 2012), the results of the present study for lichenized PB reported its high survival and re-activation potential after 18 months in anhydrobiosis under space and Mars conditions.

Considering space vacuum of $10^{-4}-10^{-7} \mathrm{~Pa}$ as well as $10^{3} \mathrm{~Pa}$ of the Mars-analogue atmosphere for 18 months, the lichens experienced a strong, long-term desiccation. Normally, the re-activation of air-dried lichens by water-uptake takes 5-20 min (Lange et al. 1989; Dyer \& Crittenden 2008), depending on the species and the dry state. The prolonged reactivation time ( 48 or $96 \mathrm{~h}$ ) of the ISS and MGR samples appears to be due to the longer time needed to moisten sufficiently after such extreme desiccation events, to re-start metabolism, to run repair processes and to re-initiate photosynthetic activity in the PB. This is supported by the correlation between elongated re-activation procedures with rising Fv/Fm values (Fig. 8). Consistently, the samples exposed in Marsanalogue atmosphere took half of the time to regain their photosynthetic activity. However, the experiment demonstrates the protective potential of the anhydrobiotic state, permitting re-activation after long-term desiccation by LEOvacuum conditions (Sánchez et al. 2014). This is consistent with former simulation experiments (de Vera et al. 2003, 2004b, 2010, 2013) and storage experiments, in which desiccated thalli of $X$. parietina (stored at $-20^{\circ} \mathrm{C}$ ), appeared fully viable after 13 years (Honegger 2003) while micro-fungi survived 13 years in liquid nitrogen (Smith 1982). Desiccated lichens also survived shock freezing in liquid nitrogen, preparation for scanning electron microscope (SEM) analyses and low-temperature SEM examination ( $20 \mathrm{kV}$ electron beam, high vacuum, Honegger 2003). Moreover, isolated PB revealed high resistance to freezing (Hájek et al. 2012; Sadowsky \& Ott 2012).

To conclude, concerning anhydrobiosis neither vacuum nor freezing appears to be the limiting factor for survival for lichen symbionts. Anhydrobiosis includes de-activation of photosystem II (Lange et al. 1989), avoiding the accumulation of reactive oxygen species (ROS), which harm essential cell functions (Wieners et al. 2012; Kranner et al. 2005). The repeated freezing and thawing cycles can be tolerated by lichens in their natural habitat in a diurnal course (Kappen 1985). The temperature fluctuations during exposition ranged between +43 and $-21.7^{\circ} \mathrm{C}$ and do not exceed the range of temperatures lichen may experience in the natural habitat. The freezing resistance of $X$. elegans was not sufficiently tested by the conditions in LIFE.

The ISS Mars-analogue samples showed slightly higher viability rates in LIVE/DEAD analysis compared with the ISS space vacuum samples. Additionally, the respective $\mathrm{Fv} / \mathrm{Fm}$ values were higher after shorter re-activation for samples exposed in Mars-analogue conditions. Depending on the length of the desiccation event the re-activation time needed was more prolonged, as indicated by the timedependent increase of $\mathrm{Fv} / \mathrm{Fm}$ in the (space) vacuum samples. The LIVE/DEAD staining results for the PB indicated less difference between the viability of Marsanalogue and space vacuum samples than the chlorophyll $a$ fluorescence data pointed to, indicating that $\mathrm{Fv} / \mathrm{Fm}$ measurements should not be the only test for viability of the $\mathrm{PB}$ in the lichen thallus.

\section{Solar irradiation/cortex layer}

In the present study, ISS and MGR lichen samples, including the isolated MB samples, lost vitality not related to the insolation applied according to the LIVE/DEAD staining analyses. This is consistent with space condition simulation experiments conducted by de Vera et al. (2003), which revealed no decrease in viability for $X$. elegans thalli irradiated with UV $(200-400 \mathrm{~nm})$ to a dose of $10 \mathrm{~kJ} \mathrm{~m}^{-2}$ applied in $4 \mathrm{~h}$, and a decrease to a minor extent after UVR $>160 \mathrm{~nm}$ up to doses of $150 \mathrm{~kJ} \mathrm{~m}^{-2}$, combined with vacuum conditions. The UVR doses of the fully insolated ISS samples accumulated to about $634 \mathrm{MJ} \mathrm{m}^{-2}$ within 559 days (Rabbow et al. 2012), not exceeding UVR-resistance of the entire lichen thalli. The high resistance to insolation of the photosynthetic partner (algae) might largely be caused by the secondary metabolite parietin deposited in the upper cortex layer (Solhaug \& Gauslaa 1996), by the algal cell clustering in the PB layer, characteristic for the genus Trebouxia (Schaper 2003) and the protection by the layered anatomical structure of the lichen thallus, mainly formed by the MB (Henssen \& Jahns 1974). 
The UV and blue light screening abilities of the secondary metabolite parietin have been discussed by several authors, mainly with respect to UV-B irradiation (e.g. Solhaug \& Gauslaa 1996; Wynn-Williams et al. 2002; Nybakken et al. 2004). For PAR insolation parietin encrusted cortices were found to screen $81 \%$ of blue, $27 \%$ of green and $1 \%$ of red wavelength ranges (Solhaug et al. 2010).

The production of the screening secondary lichen metabolites can be enhanced in the symbiotic state (Brunauer \& Stocker-Wörgötter 2005) and the amount of parietin produced has been described to be effected by UV-B in lichens colonizing irradiated sites (Solhaug et al. 2003; Nybakken et al. 2004). The parietin encrusted cortex of $X$. elegans constitutes $8 \%$ of the total thallus thickness (Meeßen et al. 2013b) hence the additional quantity of secondary metabolites is adding to the insolation protection of the sensitive PB, more than e.g. sole cortex thickness (Dietz et al. 2000; Gauslaa \& Solhaug 2004). In the anhydrobiotic (desiccated) state, the shrinkage of the lichen thallus causes a higher density of the secondary metabolite parietin, enhancing the screening and protective effect, making UV and blue light screening most efficient (Ertl 1951; Solhaug et al. 2010).

The difference in viability occurring in the two different methods used may be caused by direct UV-induced damage of the photosynthetic key components (e.g. D1 protein, Rubisco; Holzinger \& Lütz 2006).

The Mars-analogue insolation included a $200 \mathrm{~nm}$ cut-off filter, shielding the samples (Mars ac) from vacuum-UVR $(\lambda<200 \mathrm{~nm})$. Missing vacuum-UVR insolation might explain the slightly higher viability of the ISS Mars ac samples (LIVE/DEAD staining results). However, the viability rates of all ISS samples analysed were not correlated to the irradiation received. Even the dark exposed samples did not show increased viability in LIVE/DEAD staining analysis. The small increase in the viability rates of ISS Mars-analogue samples is rather due to the Mars-analogue atmosphere.

The samples studied were collected from slightly different high alpine sites. According to the intense UV-B irradiation at the different sites (Nybakken et al. 2004) the parietin production has been stimulated in slightly different amounts or might have been even altered seasonally (Solhaug \& Gauslaa 2004; Gauslaa \& McEvoy 2005). As a consequence, different viability rates of ISS or MGR insolated samples might also be caused by different concentration of parietin in the upper cortex layer.

\section{Ionizing radiation}

To assess and quantify the impact of cosmic radiation on the samples seems to be difficult, because of the relatively low accumulated doses (200-231 mGy), the complex composition of the radiation and the shielding provided by the EXPOSE-E hardware or the ISS (Berger et al. 2012). Ionizing radiation was mainly delivered by protons of the South Atlantic Anomaly (Dachev et al. 2012) and galactic cosmic heavy ions (Berger et al. 2012). It can be discussed, that the dark-exposed samples suffered from secondary radiation produced in the hardware and the final energy deposit of accelerated protons (Hausmann
2013 personal communication). Due to the sparsely differentiation of MB and PB cells (Carlile 1995) and the lichens' modular structure, single dead cells can be spared and replaced, not affecting the lichens' entire structure. Surviving cells are able to recover from radiation showing normal growth (Gannutz 1972).

\section{MGR samples}

According to both methods the viability of the MGR samples is significantly reduced compared with the ISS samples, although the MGR samples were not subjected to cosmic radiation sources above Earth level. This might be an indication to the disparity in viability of MGR and ISS samples, caused by inevitable differences in sample handling between ISS and MGR.

\section{Mars habitability}

The $X$. elegans samples exposed on the ISS in Mars-analogue conditions showed slightly higher viability and clearly higher photosynthetic activity compared with the space vacuumexposed samples. The freezing temperatures of Mars were not tested in LIFE. As all samples were in anhydrobiosis (desiccated) for the duration of the experiment their ability to thrive in Mars micro-niches remains open.

\section{Lithopanspermia hypothesis}

The Lithopanspermia hypothesis is i.e. based on a proposal by Thomson (1871), suggesting that life could survive interplanetary travel. It emphasizes the role of the rock material, protecting the micro-organism on their transfer through space, e.g. by shielding against UV irradiation (Nicholson et al. 2000; Benardini et al. 2003; Cockell 2008; Horneck et al. 2008). Despite further modifications of the hypothesis, its principle deals with the interplanetary transfer of micro-organisms, seeding life from one planet to another.

One of the basic objectives of LIFE was to obtain results on the ability of the organisms tested to survive the interplanetary transfer phase. The results of the experiments with $X$. elegans align with the results of the simulation studies and the shortterm exposure on BIOPAN 5 and 6 (Sancho et al. 2007, 2008; de la Torre et al. 2010b). The survival abilities of $X$. elegans appear not to be exhausted even by the conditions applied at the LIFE project. Though the 1.5 year mission duration is much shorter than the estimated length of a hypothetical interplanetary transfer e.g. 2.6 Myr for some Mars meteorites (Clark 2001), the results presented indicate that $X$. elegans might be able to survive a longer duration in space or might be a promising test subject for a Directed Lithopanspermia as proposed by Crick \& Orgel (1973).

\section{Acknowledgements}

The authors would like to express their sincere gratitude to the German Federal Ministry of Economics and Technology (BMWi) and the German Aerospace Center (DLR) for funding the work of Annette Brandt (50BW1216) and J.-P. de Vera (50WB0614). Our special thanks to 
Eva Posthoff for her invaluable technical support and Joachim Meeßen for stimulating discussions. The results are included in the doctoral thesis of Annette Brandt. The authors also thank the anonymous reviewers for their comments. Results of this study were presented on the 13th European Workshop on Astrobiology (EANA 2013).

\section{References}

Baqué, M., Scalzi, G., Rabbow, E., Rettberg, P. \& Billi, D. (2013). Biofilm and planktonic lifestyles differently support the resistance of the desert cyanobacterium Chroococcidiopsis under space and martian simulations. Orig. Life Evol. Biosph. 43(4-5), 377-389.

Benardini, J.N., Sawyer, J., Venkateswaran, K. \& Nicholson, W.L. (2003). Spore UV and acceleration resistance of endolithic Bacillus pumilus and Bacillus subtilis isolates obtained from Sonoran desert basalt: implications for lithopanspermia. Astrobiology 3(4), 709-717.

Berger, T., Hajek, M., Bilski, P., Körner, C., Vanhavere, F. \& Reitz, G. (2012). Cosmic radiation exposure of biological test systems during the EXPOSE-E mission. Astrobiology 12(5), 387-392.

Brunauer, G. \& Stocker-Wörgötter, E. (2005). Culture of lichen fungi for future production of biologically active compounds. Symbiosis $\mathbf{3 8}(2)$, 187-201.

Buffoni Hall, R.S., Paulsson, M., Duncan, K., Tobin, A.K., Widell, S. \& Bornman, J.F. (2003). Water-and temperature-dependence of DNA damage and repair in the fruticose lichen Cladonia arbuscula ssp. mitis exposed to UV-B radiation. Physiol. Plantarum 118(3), 371-379.

Carlile, M. J. (1995). The Success of the Hypha and Mycelium. In The Growing Fungus, ed. N.A.R. Gow und, G.M. Gadd, pp. 3-19. Springer Dordrecht, Netherlands.

Clark, B.C. (2001). Planetary interchange of bioactive material: probability factors and implications. Orig. Life Evol. Biosph. 31(1-2), 185-197.

Cockell, C.S. (2008). The interplanetary exchange of photosynthesis. Orig. Life Evol. Biosph. 38(1), 87-104.

Crick, F.H. \& Orgel, L.E. (1973). Directed panspermia. Icarus 19(3), 341-346.

Crowe, J.H., Hoekstra, F.A. \& Crowe, L.M. (1992). Anhydrobiosis. Аnnu. Rev. Physiol. 54(1), 579-599.

Dachev, T., Horneck, G., Häder, D. P., Schuster, M., Richter, P., Lebert, M. \& Demets, R. (2012). Time profile of cosmic radiation exposure during the EXPOSE-E mission: the R3DE instrument. Astrobiology 12(5), 403-411.

de la Torre, R., Horneck, G., Sancho, L.G., Scherer, K., Faciu, R., Urling, T. \& Pintado, A. (2002) Photoecological characterization of an epilithic ecosystem at a high mountain locality (Central Spain). In Proc. Second European Workshop on Exo-Astrobiology, 16-19 Sep 2002, Granz, Austria, ESA SP-518, ESA ESTEC The Netherlands, pp. 443-444.

de la Torre Noetzel, R., Sancho, L. G., Pintado, A., Rettberg, P., Rabbow, E., Panitz, C., Deutschmann, U., Reina, M. \& Horneck, G. (2007). BIOPAN experiment LICHENS on the Foton M2 mission: preflight verification tests of the Rhizocarpon geographicum-granite ecosystem. Adv. Space Res. 40(11), 1665-1671.

de la Torre Noetzel, R., Martinez Frías, J., Mateo-Martí, E., Sanchez Iñigo, F.J., García Sancho, L. \& Horneck, G. (2010a). Are lichens and cyanobacteria suitable candidates to test the theory of lithopanspermia? In EGU General Assembly Conf. Abstracts, vol. 12, p. 14713.

de la Torre, R. et al. (2010b). Survival of lichens and bacteria exposed to outer space conditions - results of the LITHOPANSPERMIA experiments. Icarus 208(2), 735-748.

de Vera, J.P. (2005). Grenzen des Überlebens: Flechten als Modellorganismen für das Potential von Adaptationsmechanismen unter Extrembedingungen. Dissertation at Heinrich-Heine University, ULB Düsseldorf, pp. 1-180.

de Vera, J.P. (2012). Lichens as survivors in space and on Mars. Fungal Ecol. 5(4), $472-479$. de Vera, J.P. \& Ott, S. (2010). Resistance of symbiotic eukaryotes. In Symbioses and Stress, ed. J. Seckbach, M. Grube, pp. 595-611, Springer, Netherlands.

de Vera, J.P., Horneck, G., Rettberg, P. \& Ott, S. (2003). The potential of the lichen symbiosis to cope with extreme conditions of outer space-I. Influence of UV radiation and space vacuum on the vitality of lichen symbiosis and germination capacity. Int. J. Astrobiol. 1(4), 285-293.

de Vera, J.P., Horneck, G., Rettberg, P. \& Ott, S. (2004a). The potential of the lichen symbiosis to cope with the extreme conditions of outer space II: germination capacity of lichen ascospores in response to simulated space conditions. Adv. Space Res. 33(8), 1236-1243.

de Vera, J.P., Horneck, G., Rettberg, P. \& Ott, S. (2004b). In the context of panspermia: may lichens serve as shuttles for their bionts in space? In Proc. Third European Workshop on Exo-Astrobiology, 18-20 November 2003, Madrid, Spain, ESA SP-545, ESA ESTEC, The Netherlands, pp. 197-198.

de Vera, J.P., Tilmes, F., Heydenreich, T., Meyer, C., Horneck, G. \& Ott, S. (2007). Potential of prokaryotic and eukaryotic organisms in Marslike environments and as a reference system for the search of life on other planets. In Proc. DGLR Int. Symp., p. 10.

de Vera, J.P., Rettberg, P. \& Ott, S. (2008). Life at the limits: capacities of isolated and cultured lichen symbionts to resist extreme environmental stresses. Orig. Life Evol. Biosph. 38(5), 457-468.

de Vera, J.P., Möhlmann, D., Butina, F., Lorek, A., Wernecke, R. \& Ott, S. (2010). Survival potential and photosynthetic activity of lichens under Mars-like conditions: a laboratory study. Astrobiology 10(2), 215-227.

de Vera, J.P., Schulze-Makuch, D., Khan, A., Lorek, A., Koncz, A., Möhlmann, D. \& Spohn, T. (2014). Adaptation of an Antarctic lichen to Martian niche conditions can occur within 34 days. Planet. Space Sci. 98, 182-190.

Dietz, S., Büdel, B., Lange, O.L. \& Bilger, W. (2000). Transmittance of light through the cortex of lichens from contrasting habitats. Bibl. Lichenol. $\mathbf{7 5}$, 171-182.

Dyer, P. \& Crittenden, P. (2008). Antarctic lichens: life in the freezer. Microbiol. Today 35(2), 74.

Eker, A.P.M., Yajima, H. \& Yasui, A. (1994). DNA photolyase from the fungus Neurospora crassa. Purification, characterization and comparison with other photolyases. Photochem. Photobiol. 60(2), 125-133.

Ertl, L. (1951). Über die Lichtverhältnisse in Laubflechten. Planta 39(3), 245-270.

Gannutz, T.P. (1972). Effects of gamma radiation on lichens - 1 . Acute gamma radiation on lichen algae and fungi. Radiat. Bot. 12, 331-338.

Gauslaa, Y. \& McEvoy, M. (2005). Seasonal changes in solar radiation drive acclimation of the sun-screening compound parietin in the lichen Xanthoria parietina. Basic Appl. Ecol. 6(1), 75-82.

Gauslaa, Y. \& Solhaug, K.A. (2004). Photoinhibition in lichens depends on cortical characteristics and hydration. Lichenologist 36(2), 133-143.

Hájek, J., Váczi, P., Barták, M. \& Jahnová, L. (2012). Interspecific differences in cryoresistance of lichen symbiotic algae of genus Trebouxia assessed by cell viability and chlorophyll fluorescence. Cryobiology 64(3), 215-222.

Hawksworth, D.L. (1988). The variety of fungal-algal symbioses, their evolutionary significance, and the nature of lichens. Bot. J. Linnean Soc. 96(1), 3-20.

Henssen, A. \& Jahns, H.M. (1974). Lichenes. Eine Einführung in die Flechtenkunde. Georg Thieme Verlag, Stuttgart, pp. 11-71.

Hoekstra, F.A., Golovina, E.A. \& Buitink, J. (2001). Mechanisms of plant desiccation tolerance. Trends Plant sci. 6(9), 431-438.

Holzinger, A. \& Lütz, C. (2006). Algae and UV irradiation: effects on ultrastructure and related metabolic functions. Micron 37(3), 190-207.

Honegger, R. (2003). The impact of different long-term storage conditions on the viability of lichen-forming ascomycetes and their green algal photobiont, Trebouxia spp. Plant Biol. 5(3), 324-330.

Horneck, G., Stöffler, D., Ott, S., Hornemann, U., Cockell, C.S., Moeller, R., Meyer, C., de Vera, J.P., Fritz, J., Schade, S. \& 
Artemieva, N.A. (2008). Microbial rock inhabitants survive hypervelocity impacts on Mars-like host planets: first phase of lithopanspermia experimentally tested. Astrobiology 8(1), 17-44.

Horneck, G., Klaus, D.M. \& Mancinelli, R.L. (2010). Space microbiology. Microbiol. Mol. Biol. Rev. 74(1), 121-156.

Huneck, S. \& Yoshimura, I. (1996). Data of lichen substances (chapter 3). In Identification of Lichen Substances. pp. 125-446. Springer, Berlin, Heidelberg.

Jensen, M. (2002). Measurement of chlorophyll fluorescence in lichens. In Protocols in Lichenology, ed. I. Kranner, R.P. Beckett, A.K. Varma, pp. 135-151. Springer Laboratory Manuals, Springer Verlag, Berlin, Heidelberg.

Kappen, L. (1985). Lichen-habitats as micro-oases in the Antarctic - the role of temperature. Polarforschung 55(1), 49-54.

Kappen, L. (2000). Some aspects of the great success of lichens in Antarctica. Antarct. Sci. 12(3), 314-324.

Kappen, L. \& Schroeter, B. (1997). Activity of lichens under the influence of snow and ice. In Proc. NIPR Symp. on Polar Biology. pp. 163-168.

Kappen, L., Schroeter, B., Scheidegger, C., Sommerkorn, M. \& Hestmark, G. (1996). Cold resistance and metabolic activity of lichens below $0^{\circ} \mathrm{C}$. Adv. Space Res. 18(12), 119-128.

Kranner, I., Cram, W.J., Zorn, M., Wornik, S., Yoshimura, I., Stabentheiner, E. \& Pfeifhofer, H.W. (2005). Antioxidants and photoprotection in a lichen as compared with its isolated symbiotic partners. Proc. Natl. Acad. Sci. USA 102(8), 3141-3146.

Kranner, I., Beckett, R., Hochman, A. \& Nash, T.H. III (2008). Desiccationtolerance in lichens: a review. Bryologist 111(4), 576-593.

Lange, O.L. (1990). Twenty-three years of growth measurements on the crustose lichen Caloplaca aurantia in the central Negev Desert. Israel J. Bot. 39(4-6), 383-394.

Lange, O.L. \& Kappen, L. (1972). Photosynthesis of lichens from Antarctica. In Antarctic research series, vol. 20 (Antarctic terrestrial biology), ed. Llano, A., pp. 83-95. American Geophysical Union.

Lange, O.L., Bilger, W., Rimke, S. \& Schreiber, U. (1989). Chlorophyll fluorescence of lichens containing green and blue-green algae during hydration by water vapor uptake and by addition of liquid water. Bot. Acta 102(4), 306-313.

Meeßen, J., Eppenstein, S. \& Ott, S. (2013a). Recognition mechanisms during the pre-contact state of lichens: II. Influence of algal exudates and ribitol on the response of the mycobiont of Fulgensia bracteata. Symbiosis 59(3), $131-143$

Meeßen, J., Sánchez, F.J., Brandt, A., Balzer, E.M., de la Torre, R., Sancho, L.G., de Vera, J.P. \& Ott, S. (2013b). Extremotolerance and resistance of lichens: comparative studies on five species used in astrobiological research I. Morphological and anatomical characteristics. Orig. Life Evol. Biosph. 43(3), 283-303.

Melosh, H.J. (1984). Impact ejection, spallation, and the origin of meteorites. Icarus 59(2), 234-260.

Meyer, C., Fritz, J., Misgaiski, M., Stoeffler, D., Artemieva, N.A., Hornemann, U., Moeller, R., de Vera, J.P., Cockell, C.S., Horneck, G., Ott, S. \& Rabbow, E. (2011). Shock experiments in support of the Lithopanspermia theory: the influence of host rock composition, temperature, and shock pressure on the survival rate of endolithic and epilithic microorganisms. Meteorit. Planet. Sci. 46(5), 701-718.

Millard, P.J., Roth, B.L., Thi, H.P., Yue, S.T. \& Haugland, R.P. (1997). Development of the FUN-1 family of fluorescent probes for vacuole labeling and viability testing of yeasts. Appl. Environ. Microbiol. 63(7), 2897-2905.

Nicholson, W.L., Munakata, N., Horneck, G., Melosh, H.J. \& Setlow, P. (2000). Resistance of Bacillus endospores to extreme terrestrial and extraterrestrial environments. Microbiol. Mol. Biol. Rev. 64(3), 548-572.

Nybakken, L., Solhaug, K.A., Bilger, W. \& Gauslaa, Y. (2004). The lichens Xanthoria elegans and Cetraria islandica maintain a high protection against UV-B radiation in Arctic habitats. Oecologia 140(2), 211-216.

Onofri, S., Selbmann, L., Zucconi, L. \& Pagano, S. (2004). Antarctic microfungi as models for exobiology. Planet. Space Sci. 52(1), 229-237.

Onofri, S. et al. (2012). Survival of rock-colonizing organisms after 1.5 years in outer space. Astrobiology 12(5), 508-516.
Ott, S. \& Sancho, L.G. (1991). Structure and adaptation of lichens to extreme environmental conditions in the maritime Antarctic (Livingston Island, South Shetland Island). In: Actas del cuarto simposio espanol de estudios antarcticos. ed. J. Castellvi, pp. 251-256. Comision Interministerial de ciencia y technologia, Madrid.

Øvstedal, D.O. \& Lewis Smith, R.I. (2001). Lichens of Antarctica and South Georgia. Cambridge University Press, Cambridge, UK, pp. 361-363.

Petersen, J.L., Lang, D.W. \& Small, G.D. (1999). Cloning and characterization of a class II DNA photolyase from Chlamydomonas. Plant Mol. Biol. 40(6), 1063-1071.

Rabbow, E. et al. (2012). EXPOSE-E: an ESA astrobiology mission 1.5 years in space. Astrobiology 12(5), 374-386.

Raggio, J., Pintado, A., Ascaso, C., de La Torre, R., de Los Ríos, A., Wierzchos, J., Horneck, G. \& Sancho, L.G. (2011). Whole lichen thalli survive exposure to space conditions: results of LITHOPANSPERMIA experiment with Aspicilia fruticulosa. Astrobiology 11(4), 281-292.

Rebecchi, L., Altiero, T. \& Guidetti, R. (2007). Anhydrobiosis: the extreme limit of desiccation tolerance. Invert. Surviv. J. 4, 65-81.

RedShift Report (2011). Reviewers: van Bavinchove, C., Beuselinck, T., EXPOSE: Environmental history by calculation - EXPOSE-E simulation results. Ref: EXP-RP-017-RS ISS. A (2). RedShift Design and Engineering BVBA (125 pp).

Sadowsky, A. \& Ott, S. (2012). Photosynthetic symbionts in Antarctic terrestrial ecosystems: the physiological response of lichen photobionts to drought and cold. Symbiosis 58(1-3), 81-90.

Sánchez, F.J., Meeßen, J., Ruiz, M., Sancho, L.G., Ott, S., Vílchez, C., Horneck, G., Sadowsky, A. \& de la Torre, R. (2014). UV-C tolerance of symbiotic Trebouxia sp. in the space-tested lichen species Rhizocarpon geographicum and Circinaria gyrosa: role of the hydration state and cortex/ screening substances. Int. J. Astrobiol. 13(1), 1-18.

Sancho, L.G., de la Torre, R., Horneck, G., Ascaso, C., de los Rios, A., Pintado, A., Wierzchos, J. \& Schuster, M. (2007). Lichens survive in space: results from the 2005 LICHENS experiment. Astrobiology 7(3), 443-454.

Sancho, L.G., de la Torre, R. \& Pintado, A. (2008). Lichens, new and promising material from experiments in astrobiology. Fungal Biol. Rev. 22(3), 103-109.

Scalzi, G., Selbmann, L., Zucconi, L., Rabbow, E., Horneck, G., Albertano, P. \& Onofri, S. (2012). LIFE Experiment: isolation of cryptoendolithic organisms from Antarctic colonized sandstone exposed to space and simulated Mars conditions on the International Space Station. Orig. Life Evol. Biosph. 42(2-3), 253-262.

Schaper, G.M. (2003). Komplexe Interaktionsmuster und die Dynamik von Entwicklungsprozessen in Flechtenökosystemen. Dissertation at the Heinrich-Heine University, ULB Düsseldorf, pp. 1-220.

Schlensog, M., Schroeter, B., Pannewitz, S. \& Green, T.G.A. (2003). Adaptation of mosses and lichens to irradiance stress in maritime and continental antarctic habitats. In Antarctic Biology in a Global Context, ed. A.H.L. Huiskes, W.W.C. Gieskes, J. Rozema, R.M.L. Schorno, S.M. van der Vies, W.J. Wolff, pp. 161-166. Backhuys Publisher, Leiden.

Schroeter, B., Green, T.G.A., Seppelt, R.D. \& Kappen, L. (1992). Monitoring photosynthetic activity of crustose lichens using a PAM2000 fluorescence system. Oecologia 92(4), 457-462.

Schuster, M., Dachev, T., Richter, P. \& Häder, D.P. (2012). R3DE: radiation risk radiometer-dosimeter on the International Space Station-optical radiation data recorded during 18 months of EXPOSE-E exposure to open space. Astrobiology 12(5), 393-402.

Shuster, D.L. \& Weiss, B.P. (2005). Martian surface paleotemperatures from thermochronology of meteorites. Science 309(5734), 594-600.

Smith, D. (1982). Liquid nitrogen storage of fungi. Trans. Br. Mycol. Soc. 79(3), 415-421.

Solhaug, K.A. \& Gauslaa, Y. (1996). Parietin, a photoprotective secondary product of the lichen Xanthoria parietina. Oecologia 108(3), 412-418.

Solhaug, K.A. \& Gauslaa, Y. (2004). Photosynthates stimulate the UV-B induced fungal anthraquinone synthesis in the foliose lichen Xanthoria parietina. Plant, Cell Environ. 27(2), 167-176.

Solhaug, K.A., Gauslaa, Y., Nybakken, L. \& Bilger, W. (2003). UVinduction of sun-screening pigments in lichens. New Phytol. 158(1), 91-100. 
Solhaug, K.A., Larsson, P. \& Gauslaa, Y. (2010). Light screening in lichen cortices can be quantified by chlorophyll fluorescence techniques for both reflecting and absorbing pigments. Planta 231(5), 1003-1011.

Stöffler, D., Horneck, G., Ott, S., Hornemann, U., Cockell, C.S., Moeller, R., Meyer, C., de Vera, J.P., Fritz, J. \& Artemieva, N.A. (2007). Experimental evidence for the potential impact ejection of viable microorganisms from Mars and Mars-like planets. Icarus 186(2), 585-588.

Thomson, W. (1871). Presidential address to the British Association for the Advancement of Science. Nature 4, 262-270.
Westall, F. (2013). Microbial scale habitability on Mars. In Habitability of Other Planets; Cellular Origin, Life in Extreme Habitats and Astrobiology, 28. Springer, Springer Dordrecht, NL, pp. 183-202.

Wieners, P.C., Mudimu, O. \& Bilger, W. (2012). Desiccation-induced nonradiative dissipation in isolated green lichen algae. Photosynth. Res. 113(1-3), 239-247.

Wynn-Williams, D.D., Edwards, H.G.M., Newton, E.M. \& Holder, J.M. (2002). Pigmentation as a survival strategy for ancient and modern photosynthetic microbes under high ultraviolet stress on planetary surfaces. Int. J. Astrobiol. 1(1), 39-49. 